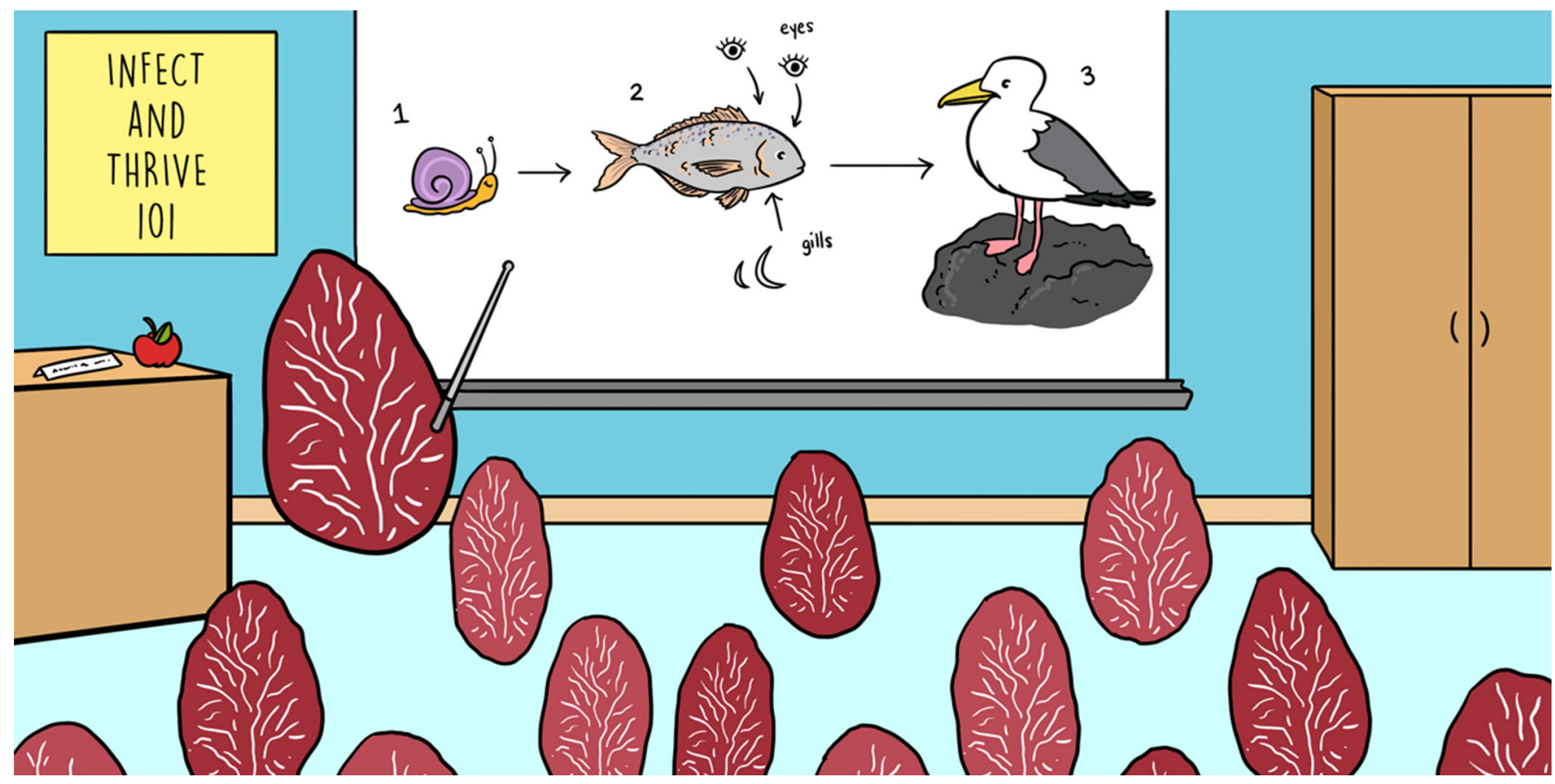

\title{
WHICH WAY TO THE BRAIN? A PARASITE'S FAVORITE ENTRY PORTALS INTO FISH
}

\section{Gabrielle S. van Beest ${ }^{1,2^{*}}$ and Ana Born-Torrijos ${ }^{1,2}$}

${ }^{1}$ Cavanilles Institute for Biodiversity and Evolutionary Biology, Science Park, University of Valencia, Valencia, Spain

2Institute of Parasitology, Biology Centre, Czech Academy of Sciences, Ceské Budéjovice, Czechia

YOUNG REVIEWERS:

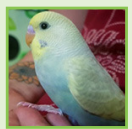

EREN

AGE: 8

(2.) SARVADEB

AGE: 9
Parasites are found all over the world and there are many different types. However, they are often overlooked due to their small size. Parasites rely on hosts to survive. Hosts are organisms that are needed for completing the parasite's life cycle. Therefore, parasites are constantly moving from one animal to another. How does this transmission between animals happen? We study how a parasite called Cardiocephaloides longicollis moves between animals and enters into their fish host. This parasite infects fish through their skin, to eventually develop in their brains. By visualizing C. longicollis with a fluorescent and glowing stain, we observed that its favorite entry portals into fish were areas close to the brain or with an easy connection to it, such as the eyes, the gills, or the back and belly areas. Our study helps us to understand one of the strategies that some parasites use to complete their life cycles. 
Figure 1

Complex life cycle of the parasite $C$. longicollis. The life cycle of this parasite includes three hosts that the parasite must move through to complete its life cycle. The immature and swimming stages of the parasite are shown in yellow and the adult stage in orange. Figure modified from Born-Torrijos et al. [3].

\section{DEFINITIVE HOST}

Organism that the parasite infects and where it develops into the adult stage, which reproduces producing eggs that are released into the environment through the definitive host's feces.

\section{LARVAE}

Youth stage before transformation into an adult. For example, before becoming a butterfly, the larva was a caterpillar.

\section{INTERMEDIATE HOST}

Organism that the parasite infects and where it develops as a larval stage. Intermediate hosts are needed for some parasites to complete their life cycles.

\section{CERCARIAE}

The name for the larval stage that some parasites go through during development. Some cercariae can freely swim in the water to infect their hosts.

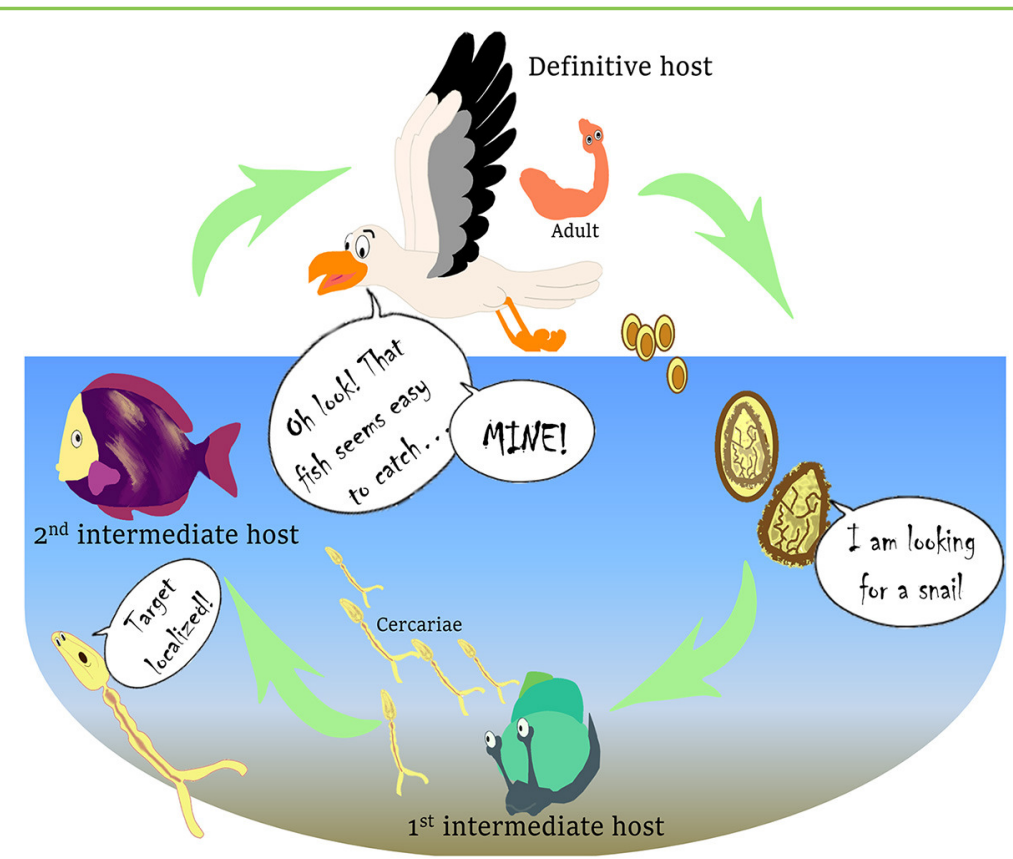

Figure 1

\section{WHAT ARE PARASITES?}

Parasites are living organisms that rely on another organism to survive. The word is derived from the Greek word "parásitos," which means "one who eats at the table of another." The parasite usually benefits from this relationship by feeding off nutrients from the chosen organism, called the host, and sometimes also uses the host as a place to take refuge and reproduce. In parasite-host interactions, hosts evolve defense mechanisms to fight the parasitic infection, but parasites, in turn, come up with new strategies to find or survive in their hosts [1]. Some parasites have a simple life cycle, in which they need only one host species to develop and reproduce. This host, in which the parasite develops into its adult stage and reproduces, is called the definitive host. In other cases, parasites have a complex life cycle that involves more than one host species, sometimes even three (Figure 1). In a typical complex life cycle, the parasite reproduces in the definitive host, usually a vertebrate, such as a bird or a fish, which then releases parasite eggs into the environment through its feces. The eggs hatch to release larvae that can infect the first intermediate host, usually an invertebrate, such as a snail. These larvae reproduce within this intermediate host and thousands of immature free-living and swimming stages, called cercariae, are released into the environment, where they infect a second intermediate host, usually a fish or another invertebrate. Cercariae grow and mature within this host, developing into another stage called a metacercariae, and the cycle is completed when the definitive host eats the second intermediate host. Does this make you wonder how these parasites succeed in completing their life cycle when it seems so challenging? 


\section{ARE PARASITES LUCKY TO RUN INTO THEIR HOSTS BY CHANCE?}

In order to infect a host, parasites first have to find it in their environment, and for this, they develop what we call transmission strategies, or ways of finding and successfully infecting a host. Sometimes, parasites can be transmitted when an infected host is consumed by a predator that just happens to be the next host for the parasite. Then, the parasite infects this host and the life cycle continues. On other occasions, more than just luck is involved, and parasites actively increase their chances of transmission in various ways. One common strategy is by influencing the host's behavior, to make contact with the next host easier. For example, the parasite Gyrodactylus bullatarudis uses the colorful guppy fish as a host, infecting its gills and changing how the fish swim. Healthy guppies meet with the infected ones because they are attracted to their strange swimming behavior, which is caused by the infection with the parasite [2]. In this way, the parasite infection spreads among the healthy fish. Another example of a parasite manipulating its host's behavior to improve transmission, occurs when fish are infected with Schistocephalus solidus. Infected fish become an easy prey for the predators, which can be the next host, by influencing the infected fish to seek food while ignoring the presence of predators that could eat them. Similarly, common dace fish infected with the eye fluke Diplostomum spathaceum spend more time in the more sunlit surface water than uninfected fish do, becoming easier for birds, their next host, to catch [2].

\section{WHAT ARE WE INVESTIGATING?}

We studied a parasite called Cardiocephaloides longicollis, whose name is derived from Latin and helps to remember what the adult stage looks like: a heart shaped-head with a very long neck (Figure 1). We investigated the strategies used by the larval stages of C. longicollis to enter into their fish hosts. This parasite is widespread along the Mediterranean coast and it infects wild and farm-raised fish, such as the gilthead seabream (Sparus aurata), one of the most important marine fishes in Mediterranean aquaculture [3]. In its complex life cycle, C. longicollis uses marine snails and fish as first and second intermediate hosts, and seagulls as definitive hosts (Figure 1). The cercariae are released from the snails and, despite their short life span, they are able to reach the fish host. After getting into the fish through the skin, they move through the tissues toward the head to infect the brain, where $C$. longicollis cercariae mature and form cysts, the metacercariae. There, the parasite waits until the fish is eaten by a seagull, the definitive host.

How do C. longicollis cercariae find their way from the snails to the fish? Bartoli and Prévot [4] suggested that C. longicollis cercariae, once 
Figure 2

C. longicollis cercariae are transparent, so we marked them with fluorescence to be able to see and locate them on the fish's body surface. See how they look before (left) and after (center) they are marked with

fluorescent stain. You can also see how a cercariae looks under the microscope used to examine the infected fish (right): a stained cercaria (indicated by a white arrow) tries to enter through the fish's eye $(100 \mu \mathrm{m}=0.004 \mathrm{in}$ and $1 \mathrm{~mm}=0.04 \mathrm{in}$ ).

\section{FLUORESCENT}

Glowing. In this case, cercariae were stained with a fluorescent stain to make them brighter and to help us to recognize and locate them on the fish surface.

\section{BEFORE staining AFTER staining Cercaria entering fish}
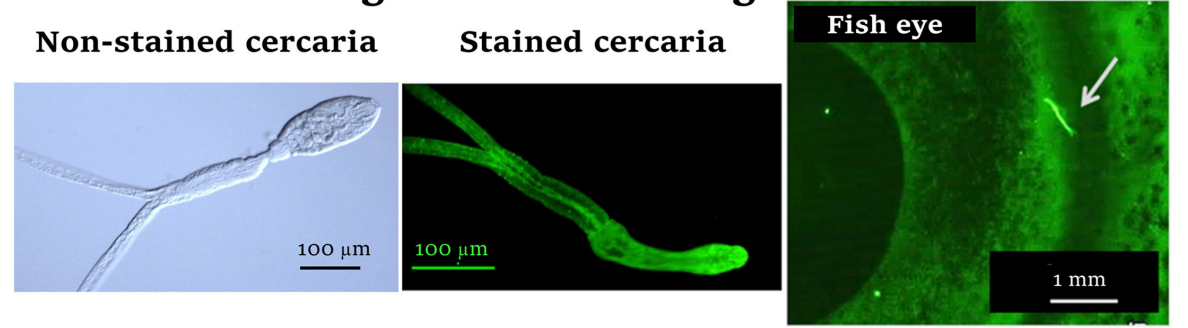

Figure 2

they are released from the snail, can get closer to the fish host, by swimming toward sunlight and meeting the fish in the water column. We asked ourselves whether C. longicollis cercariae, similar to other parasites, have a special kind of transmission strategy once they get in contact with the fish. For instance, Centrocestus armatus cercariae specifically enter the host through the gills [5] and Diplostomum spathaceum cercariae infect the fish eyes by first penetrating the gills and the skin [6]. So, to understand the host-parasite interaction (the relationship between cercariae and fish), we studied the exact spots or entry portals that cercariae use to infect the fish.

\section{CERCARIAE'S FAVORITE ENTRY PORTALS INTO THE FISH'S BODY}

To study the transmission strategy of $C$. longicollis cercariae, we first had to be able to see the cercariae on the fish's body surface. As shown in Figure 2, cercariae are small and transparent, so marking them with a fluorescent stain allowed us to visualize them quickly, as shining-fluorescent cercariae. In our experiment, fifteen $S$. aurata fish were each infected with 100 stained cercariae. After infection, fish were placed in a dark box with enough seawater to cover them and we observed their surfaces under a special microscope to locate the shining-fluorescent cercariae. We recorded the exact locations cercariae used when trying to penetrate into the fish, using a paper map of the fish's body. After repeating this process with the fifteen fish, we put together a database summarizing the information on the entry portals of the cercariae. We performed mathematical analyses to see if there were differences in the concentration of cercariae between the different areas of the fish's body, and our analysis showed that cercariae followed a specific strategy. The heat map shown in Figure 3A uses different colors to represent the concentrations of cercariae, with the yellowish areas being the ones with more cercariae. This heat map shows the cercariae's favorite entry portals - the body areas used most often to infect the fish hosts. Cercariae were detected along the entire fish body, but they were especially concentrated in areas close to the head, the eyes, and the gills, as well as around the back and belly areas of the fish (Figure 3B). 
Figure 3

Entry portals into fish used by $C$. longicollis cercariae. (A) Heat map, with brighter yellowish colors indicating spots where we found a higher concentration of cercariae trying to get into the fish. (B) The favorite entry portals that C. longicollis cercariae use to penetrate into the fish.

\section{PELVIC GIRDLES}

Parts of the fish skeleton that bridge the space between the pelvic fins.

\section{ECOSYSTEM}

Is made up of all the living organisms and non-living material. Living organisms are part of a community in which members interact with each other and with the material around them.
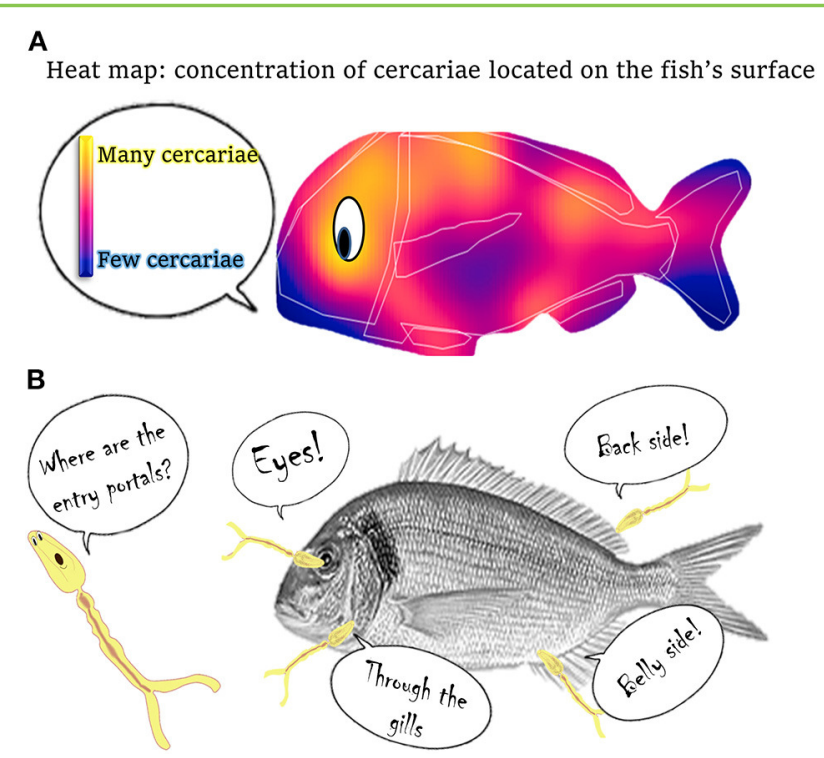

Figure 3

\section{WHAT DOES THIS MEAN?}

The ultimate goal of cercariae is to reach the fish's brain, which is their target organ. In the brain, the cercariae mature and wait for a hungry seagull to consume the infected fish. Our study suggests that $C$. longicollis cercariae try to penetrate into fish by concentrating around certain areas more often than others. Therefore, these areas might be attractive for cercariae because of how close they are to the fish's brain or because they provide easy paths to reach it. The brain is not far from the eyes, so cercariae penetrating through the eyes can reach the brain easily. Likewise, penetration through the belly area might be related to the proximity of the pelvic girdles to the head region in this fish species. Penetrating through the gills might provide direct access to the blood in the circulatory system, which could act as a highway to the final destination in the brain. By penetrating through the back area, cercariae could use the spinal cord and nerves as highways to the brain.

Our results showed that $C$. longicollis cercariae selected strategic entry portals to reach the brains of the fish, showing that parasites with such an interesting and complex life cycle do not depend only on luck-they have developed specific, successful methods to reach and infect their next host. Studying C. longicollis and its relationship with its host gives us great information on parasite-host interactions and provides a better understanding of the infection and penetration strategies that a larval stage can develop to complete its life cycle. Getting to know parasites is difficult given their complex life cycles and sizes, but the study of their transmission strategies is important because it provides information on our surrounding ecosystems and the organisms living and interacting in them. 


\section{ACKNOWLEDGMENTS}

We were grateful to Justin T. H. Chan for his valuable comments on the final manuscript.

\section{ORIGINAL SOURCE ARTICLE}

van Beest, G. S., Villar-Torres, M., Raga, J. A., Montero, F. E., and Born-Torrijos, A. 2019. In vivo fluorescent cercariae reveal the entry portals of Cardiocephaloides longicollis (Rudolphi, 1819) Dubois, 1982 (Strigeidae) into the gilthead seabream Sparus aurata L. Parasit. Vectors 12:92. doi: 10.1186/s13071-019-3351-9

\section{REFERENCES}

1. Poulin, R. 1995. "Adaptive" changes in the behaviour of parasitized animals: a critical review. Int. J. Parasitol. 25:1371-83. doi: 10.1016/0020-7519(95)00100-X

2. Dobson, A. P. 1988. The population biology of parasite-induced changes in host behavior. A review. Q. Rev. Biol. 63:139-65. doi: 10.1086/415837

3. Born-Torrijos, A., Poulin, R., Pérez-del-Olmo, A., Culurgioni, J., Raga, J. A., and Holzer, A. S. 2016. An optimised multi-host trematode life cycle: fishery discards enhance trophic parasite transmission to scavenging birds. Int. J. Parasitol. 46:745-53. doi: 10.1016/j.jpara.2016.06.005

4. Bartoli, P., and Prévot, G., 1986. Stratégies d'infestation des hôtes cibles chez les trématodes marins parasites de Larus cachinnans michaellis de Provence. Ann. Parasitol. Hum. Comp. 61:533-52. doi: 10.1051/parasite/1986615533

5. Paller, V. G. V., and Uga, S. 2008. Attachment and penetration of Centrocestus armatus (Digenea: Heterophyidae) cercariae to gills of secondary intermediate fish hosts. J. Parasitol. 94:578-83. doi: 10.1645/GE-1402.1

6. Karvonen, A., Seppälä, O., and Valtonen, E. T. 2004. Eye fluke-induced cataract formation in fish: quantitative analysis using an ophthalmological microscope. Parasitology 129:473-8. doi: 10.1017/S0031182004006006

SUBMITTED: 29 October 2019; ACCEPTED: 14 February 2020; PUBLISHED ONLINE: 05 March 2020.

EDITED BY: Vishal Shah, West Chester University, United States

CITATION: van Beest GS and Born-Torrijos A (2020) Which Way to the Brain? A Parasite's Favorite Entry Portals Into Fish. Front. Young Minds 8:25. doi: 10.3389/ frym.2020.00025

CONFLICT OF INTEREST: The authors declare that the research was conducted in the absence of any commercial or financial relationships that could be construed as a potential conflict of interest.

COPYRIGHT () 2020 van Beest and Born-Torrijos. This is an open-access article distributed under the terms of the Creative Commons Attribution License (CC BY). 

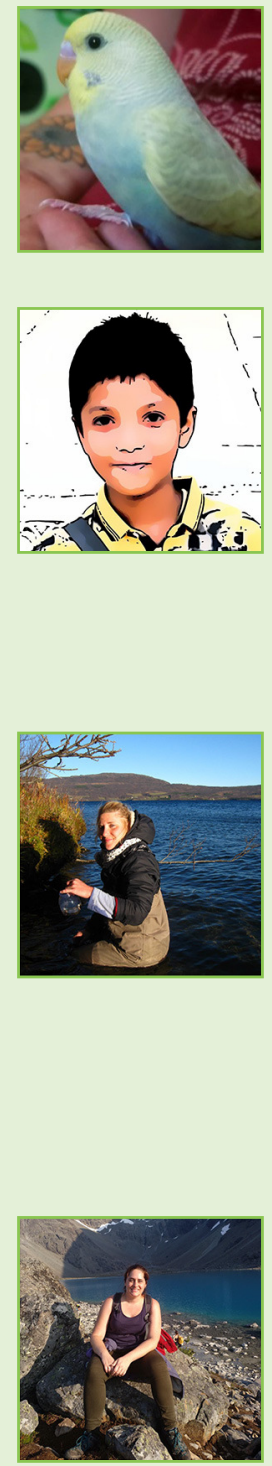

The use, distribution or reproduction in other forums is permitted, provided the original author(s) and the copyright owner(s) are credited and that the original publication in this journal is cited, in accordance with accepted academic practice. No use, distribution or reproduction is permitted which does not comply with these terms.

\section{YOUNG REVIEWERS}

\section{EREN, AGE: 8}

My name is Eren. I am 8 and I like birdwatching. I am in year 2. I like screens. I like going to good birdwatching places. There is always a target bird I am after when I go to birdwatching places. I also like reading Paul Jennings books because they are really weird and cool.

\section{SARVADEB, AGE: 9}

Sarva is talented in thinking and analyzing the things in nature. He has written different ideas in his notebook from when he was 7 . He is reluctant to close the book he is reading. His father is a renowned scientist. His favorite food is pizza and milk. He is a good swimmer.

\section{AUTHORS}

\section{GABRIELLE S. VAN BEEST}

During my studies of Biology at the University of Valencia (UV), I started to learn about parasites and I fell in love with them! I was so amazed that I began collaborating with the Zoology Unit from the Cavanilles Institute for Biodiversity and Evolutionary Biology. There, I met Dr. Ana Born-Torrijos, who was working with a very cool parasite Cardiocephaloides longicollis (trematode worm). Currently, I am a Ph.D. student at the UV, studying $C$. longicollis transmission and infection strategies. I also investigate freshwater parasites at the Institute of Parasitology (BC CAS) in the Czech Republic. *gavanbe@alumni.uv.es

\section{ANA BORN-TORRIJOS}

I was born in Spain, and since I was a child, I have been interested in animals, being especially curious about their behavior. When I grew up, I studied Biology and completed my M.Sc. in Biodiversity at the University of Valencia (Spain). I continued studying parasites and completed my Ph.D. thesis on life cycles and transmission strategies of parasites called digenean trematodes in coastal habitats. Thereafter, I decided to move to the Czech Republic, where I continue my research at the Institute of Parasitology (BC CAS), investigating parasite-host interactions, ecological parasitology and transmission dynamics. 